\title{
A influência do laboratório no tratamento da ceratite infecciosa
}

\author{
The influence of the laboratory \\ in the treatment of the infectious keratitis
}

Flávia Pelinsari Lana1, Vera Lucia Degaspare Monte Mascaro², Maria Emília Xavier Santos Araújo ${ }^{3}$

\begin{abstract}
ResUMo
Objetivo: Avaliar a resposta terapêutica das ceratites infecciosas e sua correlação com o resultado laboratorial. Métodos: Foram estudados 62 casos retrospectivamente de ceratite infecciosa de moderada à grave, atendidos no Hospital do Servidor Público Estadual de São Paulo no período de janeiro de 2000 a dezembro de 2006. Foi avaliada a resposta ao tratamento tópico com colírios antibióticos (Cefalotina $50 \mathrm{mg} / \mathrm{ml}$ e Gentamicina $14 \mathrm{mg} / \mathrm{ml}$ ou Ciprofloxacino 0,3\%), verificando-se a necessidade de modificação da terapêutica inicial de acordo com a evolução clínica e correlação com os testes microbiológicos pré-tratamento. Resultados: Observou-se que 21 culturas $(33,9 \%)$ foram positivas e 41 (66,1\%) foram negativas. Houve crescimento de fungo em uma amostra (1,6\%). Em apenas dois casos $(3,5 \%)$ houve correlação do exame bacterioscópico com o da cultura. Em 5 casos $(8,1 \%)$ houve necessidade de modificação da medicação devido à piora clínica e 91,9\% dos pacientes cursaram com cura do processo infeccioso com o tratamento inicial instituído. Conclusão: O uso tópico de antibióticos fortificados ou quinolonas foi eficaz no tratamento das ceratites de provável etiologia infecciosa com culturas positivas e negativas.

Descritores: Úlcera da córnea/quimioterapia; Cefalotina/uso terapêutico; Gentamicinas/ uso terapêutico; Ciprofloxacino/ uso terapêutico; Agentes antibacterianos/uso terapêutico; Testes de sensibilidade microbiana
\end{abstract}

\section{Abstract}

Purpose: To evaluate the initial treatment of infectious keratitis, evolution and their correlation with laboratory tests. Methods: 62 cases of infectious corneal ulcers seen in the Hospital do Servidor Público Estadual - São Paulo underwent Gram staining and culture for bacterial and fungus. Treatment with fortified Cefalotine $(50 \mathrm{mg} / \mathrm{ml})$ and Gentamicin $(14 \mathrm{mg} / \mathrm{ml})$ or fluoroquinolone 0,3\% was started. Results: 21 cultures (33,9\%) were positive for bacterial infection and 41 (66,1\%) showed no growth. Just one case was positive for fungus (1,61\%). In 2 cases (3,5\%) the Gram staining showed correlation with the culture. Five cases $(8,8 \%)$ did not respond to the initial treatment and had the medications changed and $91,9 \%$ responded to the initial clinical treatment. Conclusion: Ours results showed that combination of fortified eye drops or quinolones was efficient to treat infectious corneal ulcers with positive or negative cultures.

Keywords: Corneal ulcers/drug therapy; Cephalotin/therapeutic use; Gentamicins/therapeutic use; Ciprofloxacin/therapeutic use; Antibacterial agents/therapeutic use; Microbial sensitivity tests

\footnotetext{
1 Residente de Oftalmologia do Serviço de Oftalmologia do Hospital do Servidor Público Estadual de São Paulo "Francisco Morato de Oliveira" - (HSPE-FMO) - São Paulo (SP), Brasil;

${ }^{2}$ Doutora em Oftalmologia; Preceptora do Setor de Córnea e Patologia Externa do Hospital do Servidor Público Estadual de São Paulo "Francisco Morato de Oliveira" - (HSPE-FMO) - São Paulo (SP), Brasil;

${ }^{3}$ Preceptora do Setor de Córnea e Patologia Externa do Hospital do Servidor Público Estadual de São Paulo "Francisco Morato de Oliveira" - (HSPE-FMO) - São Paulo (SP), Brasil.
}

Os autores declaram inexistir conflitos de interesse.

Recebido para publicação em: 23/3/2010 - Aceito para publicação em 28/6/2011 


\section{INTRODUÇÃO}

A úlcera de córnea é uma condição grave, já que constitui causa importante de baixa acuidade visual. Diagnóstico e tratamento imediatos podem limitar a perda de tecido, minimizar a cicatrização e diminuir a necessidade de cirurgia futura. ${ }^{(1)}$

Tem-se observado marcada disparidade entre a literatura, que preconiza exames microbiológicos de rotina, bacterioscopia e cultura, e antibiograma, antes da instituição do tratamento de úlcera corneana infecciosa ${ }^{(2)}$ e a prática usual da comunidade oftalmológica $^{(3)}$.

No estudo realizado em Hospital Universitário do Estado de São Paulo ${ }^{(4)}$ enfatiza-se que apesar de $60 \%$ dos pacientes terem sido examinados por oftalmologistas, $45 \%$ tinham conduta não convencional $(20 \%$ sem medicação, $15 \%$ não sabiam o que usavam, $5 \%$ com colírio anestésico e 5\% com adstringente ocular) e dos $55 \%$ que faziam uso de antibióticos, apenas 4 faziam uso de antibiótico tópico e os demais a associação de antibiótico tópico com corticosteróides, antivirais e/ou antifúngicos.

McLeod et al. concluíram que a maioria das úlceras de córnea adquiridas na comunidade se resolvem com antibioticoterapia empírica de amplo espectro, sendo apenas $8,64 \%$ das infecções fúngicas ${ }^{(5)}$. Entretanto em países quentes como o Brasil, a infecção fúngica pode ser muito frequente e o início de antibioticoterapia empírica pode ser perigoso. O resultado da cultura de córnea e seu impacto na decisão terapêutica está bem estabelecido na literatura ${ }^{(6)}$.

Este trabalho tem como objetivo avaliar a resposta terapêutica inicial instituída para as úlceras corneanas infecciosas e sua evolução, correlacionandoas com os achados laboratoriais.

\section{MÉTOdos}

Realizou-se um estudo clínico prospectivo envolvendo pacientes com diagnóstico de úlcera de córnea (UCI) moderada à grave, atendidos no Setor de Córnea e Doenças Externas Oculares do Hospital do Servidor Público Estadual de São Paulo (HSPE), no período de janeiro de 2000 a dezembro de 2006.

Foi instituído um protocolo constituído de história, com ênfase em fatores predisponentes sistêmicos e oculares, acuidade visual inicial e final, classificação quanto à gravidade da úlcera, tratamento antimicrobiano prévio e instituído após colheita de material, troca de medicação, microscopia óptica pelas colorações Gram e Giemsa e cultura da úlcera com respectivo agente isolado e evolução do quadro oftalmológico. Foram consideradas úlceras graves, quando ocorrem em posição central, com diâmetro igual ou maior que $4 \mathrm{~mm}$, e com mais de T! de profundidade; úlceras moderadas com localização periférica, diâmetro menor que $4 \mathrm{~mm}$ e com menos de $\mathrm{T}$ ! de profundidade.

A colheita do material foi realizada conforme descrito na literatura ${ }^{(1)}$.

O esfregaço foi colocado em lâminas para coloração de Gram e Giemsa e em placas de cultura de Ágar sangue, Ágar chocolate, Ágar Sabouraud e meio líquido enriquecido (tioglicolato).

A microscopia óptica pela coloração de Gram e cultura foram efetuados pelo laboratório geral de Bacteriologia e coloração de Giemsa pelo laboratório de Anatomia Patológica. Foram feitas identificações dos micro-organismos recuperados pelos métodos manuais recomendados pelo "Manual of Microbiology" ou por sistemas automatizados "Vitek" (Biolar-Menieux) e testes de sensibilidade pelo método de difusão de Kirby e Bauer. As culturas foram consideradas negativas após 5 dias de incubação para bactérias e 15 dias para fungos.

Os pacientes foram submetidos ao tratamento com colírios fortificados de Cefalotina $(50 \mathrm{mg} / \mathrm{ml})$ e Gentamicina $(14 \mathrm{mg} / \mathrm{ml})$ em úlceras graves, ou Ciprofloxacino $0,3 \%$ em úlceras de gravidade moderada. Os colírios fortificados foram manipulados pelos próprios residentes envolvidos no protocolo quando não se obtinha comercialmente. Para manipulação do colírio de cefalotina foi adicionado $20 \mathrm{~mL}$ de água para injeção no frasco de $1 \mathrm{~g}$ de cefalotina e para o colírio de gentamicina foi adicionado $4 \mathrm{~mL}$ de água para injeção em uma ampola de $80 \mathrm{mg} / 2 \mathrm{~mL}$ de gentamicina. Os pacientes foram orientados quanto à necessidade de refrigeração dos mesmos. Realizou-se troca do antibiótico de acordo com a evolução clínica e com auxílio do resultado laboratorial.

Foi considerado critério de cura do processo infeccioso: a redução da dor, resolução do infiltrado corneano e do edema estromal, reepitelização e desaparecimento da reação de câmara anterior ${ }^{(5)}$.

Para análise estatística foi utilizado o teste de Kruskal Wallis. Definiu-se como significância estatística valores de $\mathrm{p}<0,05$. Este estudo foi submetido e aprovado pelo Comitê de Ética em Pesquisa do Hospital do Servidor Público Estadual de São Paulo nº 113/08. 


\section{Resultados}

O estudo somou 62 casos de UCI em 62 pacientes sendo todas amostras processadas para microscopia e cultura, 35 pacientes $(56,45 \%)$ do sexo feminino e 27 $(43,5 \%)$, masculino. A faixa etária variou de 5 a 87 anos. Destes, 41 pacientes, ou seja, $66,12 \%$ da amostra, tinham mais de 65 anos.

Vinte e uma culturas foram positivas $(33,9 \%)$ e 41 negativas $(66,1 \%)$. Entre as culturas negativas, 14 (34\%) foram colhidas na vigência do uso de antibiótico tópico, e nas culturas positivas apenas um paciente $(4,8 \%)$ usava colírio previamente à colheita, Ofloxacino $0,3 \%$. Apenas $2(3,2 \%)$ esfregaços foram considerados positivos para a presença de bactérias na coloração Gram, Nestes casos foi evidenciada correlação entre a microscopia optica pelas colorações Gram e Giemsa e a cultura(Gram positivo - cultura positiva para Staphylococus aureus e Gram negativo- cultura posivita para Proteus mirabilis) na Tabela 1.

Os agentes etiológicos isolados são apresentados

Fatores de riscos para o aparecimento de úlcera corneana infecciosa foram encontrados em 45 pacientes $(72,6 \%)$, discriminados na tabela 2.

Os pacientes foram tratados com antibióticos tópicos fortificados (Cefalotina $50 \mathrm{mg} / \mathrm{ml}$ e Gentamicina $14 \mathrm{mg} / \mathrm{ml})$ em 41 casos $(66,1 \%)$ devido à gravidade da úlcera e 21 pacientes $(33,9 \%)$ foram tratados somente com colírio de Ciprofloxacino 0,3\% por se tratarem de úlceras classificadas como moderadas.

Das 62 UCI, 5 (8,1\%) apresentaram piora clínica e foram submetidas à mudança da medicação. Quatro pacientes fizeram uso de Vancomicina e Amicacina colírios fortificados. Estes pacientes apresentaram resultados laboratoriais negativos tanto para culturas e esfregaços. Sendo assim, não houve realização de antibiograma. Um pacientes fez uso de antifúngico Anfotericina B $0,15 \%$ colírio de $1 / 1$ hora e Itraconazol $400 \mathrm{mg} /$ dia via oral (ceratite por Curvularia sp), cultura positiva apenas após biópsia corneana.

Foi necessário tratamento concomitante para resolução do processo de afinamento corneano secundário às alterações de superfície em 14 (22,58\%) pacientes, transplante de córnea ( 8 olhos), tarsorrafia temporária (5 olhos), recobrimento conjuntival ( 2 olhos) e adesivo tecidual ( 1 olho). Nestes casos obtivemos 6 (42,85\%) com culturas positivas. Os resultados das culturas e o respectivo tratamento complementar estão expostos na tabela 3.
Todos os 62 casos de UCI (100\%) evoluíram com cura do processo infeccioso com o tratamento instituído. Segundo o critério utilizado.

A tabela 4 resume os resultados laboratoriais com os respectivos tratamentos.

\section{Dıscussão}

A dificuldade e o custo dos exames laboratoriais feitos em Hospital geral provoca discussão sobre a real necessidade de realização de microscopia óptica pelas colorações de Gram e Giemsa e cultura pré-tratamento de rotina nas ceratites infecciosas, a despeito do alto índice de cura com o uso empírico dos colírios tópicos fortificados. A frequência de culturas positivas varia e nesse estudo foi encontrado $33,9 \%$, número inferior aos estudos de McLeod et al. $(69,1 \%)^{(5)}$ e de Oliveira et al. (70,8\%) na mesma instituição (HSPE) em julho de 1997 a dezembro de 1999(7). Apesar da diminuição da positividade nas culturas realizadas no mesmo laboratório $(33,9 \times 70,8 \%)$, a mudança da terapia inicial $(8,1$ X 12,5\%) e o índice de cura foram semelhantes ${ }^{(7)}$.

Entretanto, como justificar essa diferença se as colheitas nos dois estudos foram feitas seguindo o mesmo protocolo e as avaliações feitas pelo mesmo laboratório? A colheita incorreta, a escassez do material, uso prévio de antibiótico (14 pacientes) ou o fato de ser um hospital geral não contando com laboratório específico poderia justificar esses resultados? Em pacientes que receberam terapia empírica antes da análise microbiológica, levando ao alto índice de negatividade das culturas $(\mathrm{p}=0.01)$, um atraso no tratamento antibiótico foi notado.

Dos organismos identificados na cultura, os mais encontrados nesse estudo foram Staphylococcus aureus, Streptococcus pneumoniae e Pseudomonas aeruginosa resultados semelhantes a outros estudos. ${ }^{(5-7)}$

Para todos pacientes com suspeita de ceratite infecciosa foram solicitados exames microbiológicos com positividade de apenas $3,2 \%$, contrariando estudos como em outras instituições brasileiras onde o índice de positividade chega a $90,29 \%{ }^{(8)}$.

Estudo semelhante realizado em Uberlândia, Minas Gerais, obteve cultura positiva em $49,23 \%$ dos casos, predominantemente por fungos $(56,25 \%)$. Sendo o trauma o principal fator de risco. ${ }^{(9)}$ Dos 62 pacientes, $72,6 \%$ apresentaram algum fator de risco para UCI, sendo a ceratopatia bolhosa a mais prevalente. Contrariando o estudo de Rodman et al. ${ }^{(10)}$ que relataram poucos fatores de risco predisponentes e Jeng et al. em que $55 \%$ dos 
Tabela 1

Agentes isolados de pacientes com ceratite infecciosa

\begin{tabular}{lr}
\hline Micro-organismo & Número (\%) \\
\hline Staphylococus aureus & $6(28,6)$ \\
Streptococus pneumoniae & $3(14,3)$ \\
Pseudomonas aeruginosa & $2(9,5)$ \\
Staphylococcus coagulase negativo & $2(9,5)$ \\
Proteusmirabilis & $2(9,5)$ \\
Serratiamarcecens & $2(9,5)$ \\
Curvularia sp. & $1(4,75)$ \\
Haemophilus sp. & $1(4,75)$ \\
Enterococusfecalis & $1(4,75)$ \\
Corynebacterium & $1(4,75)$ \\
Total & $21(100)$ \\
\hline
\end{tabular}

Tabela 2

Fatores de risco em 46 pacientes com ceratite infecciosa

\begin{tabular}{lr}
\hline Fator de risco & Número $\mathbf{( \% )}$ \\
\hline Ceratopatia bolhosa & $8(17,4)$ \\
Pós-transplante de córnea & $7(15,2)$ \\
Diabetes Mellitus & $7(15,2)$ \\
Cirurgia ocular anterior & $6(13,0)$ \\
Olho seco & $5(10,9)$ \\
Trauma ocular & $4(8,7)$ \\
Herpes simples & $3(6,5)$ \\
Tracoma & $2(4,3)$ \\
Distrofia de Fuchs & $1(2,2)$ \\
Atopia & $1(2,2)$ \\
Lente de contato & $1(2,2)$ \\
Total & $45(72,6)$ \\
\hline
\end{tabular}

Tabela 3

Pacientes que necessitaram de tratamento cirúrgico complementar

\begin{tabular}{lll}
\hline Procedimento cirúrgico & Cultura & Antibiótico tópico \\
\hline Transplante de córnea & + & Cefalo $50 \mathrm{mg} / \mathrm{ml}+$ gentamicina $14 \mathrm{mg} / \mathrm{ml}$ \\
Transplante de córnea & + & Quinolona de $2^{\text {a }}$ geração \\
Transplante de córnea & + & Cefalo $50 \mathrm{mg} / \mathrm{ml}+$ gentamicina $14 \mathrm{mg} / \mathrm{ml}$ \\
Transplante de córnea & + & Cefalo $50 \mathrm{mg} / \mathrm{ml}+$ gentamicina $14 \mathrm{mg} / \mathrm{ml}$ \\
Transplante de córnea & - & Cefalo $50 \mathrm{mg} / \mathrm{ml}+$ gentamicina $14 \mathrm{mg} / \mathrm{ml}$ \\
Transplante de córnea & - & Cefalo $50 \mathrm{mg} / \mathrm{ml}+$ gentamicina $14 \mathrm{mg} / \mathrm{ml}$ \\
Transplante de córnea & - & Cefalo $50 \mathrm{mg} / \mathrm{ml}+$ gentamicina $14 \mathrm{mg} / \mathrm{ml}$ \\
Transplante de córnea & - & Cefalo $50 \mathrm{mg} / \mathrm{ml}+$ gentamicina $14 \mathrm{mg} / \mathrm{ml}$ \\
Tarsorrafia & - & Cefalo $50 \mathrm{mg} / \mathrm{ml}+$ gentamicina $14 \mathrm{mg} / \mathrm{ml}$ \\
Tarsorrafia & - & Quinolona de $2^{\text {a geração }}$ \\
Tarsorrafia & - & Cefalo $50 \mathrm{mg} / \mathrm{ml}+$ gentamicina $14 \mathrm{mg} / \mathrm{ml}$ \\
Tarsorrafia & - & Cefalo $50 \mathrm{mg} / \mathrm{ml}+$ gentamicina $14 \mathrm{mg} / \mathrm{ml}$ \\
Tarsorrafia & + & Quinolona de 2 geração \\
Recobrimento conjuntival & + & Cefalo $50 \mathrm{mg} / \mathrm{ml}+$ gentamicina $14 \mathrm{mg} / \mathrm{ml}$ \\
Recobrimento conjuntival & - & Cefalo $50 \mathrm{mg} / \mathrm{ml}+$ gentamicina $14 \mathrm{mg} / \mathrm{ml}$ \\
Adesivo tecidual & - & Cefalo $50 \mathrm{mg} / \mathrm{ml}+$ gentamicina $14 \mathrm{mg} / \mathrm{ml}$ \\
\hline
\end{tabular}

$+=$ cultura positiva, $-=$ cultura negativa

Tabela 4

Classificação das úlceras e sua correlação com o resultado laboratorial

\begin{tabular}{|c|c|c|c|c|c|}
\hline \multirow[t]{2}{*}{ Antibiótico tópico } & & \multicolumn{4}{|c|}{ Classificação das úlceras } \\
\hline & \multicolumn{3}{|c|}{ Moderada } & \multicolumn{2}{|r|}{ Grave } \\
\hline \multirow{6}{*}{$\begin{array}{l}\text { Quinolona } 2^{\mathrm{a}} \text { geração } \\
\text { Cefalotina } 50 \mathrm{mg} / \mathrm{ml}+ \\
\text { Gentamicina } 14 \mathrm{mg} / \mathrm{ml} \\
\text { Troca de antibiótico tópico }\end{array}$} & & 21 & & & 0 \\
\hline & & 0 & & & 41 \\
\hline & & & & & \\
\hline & & 0 & & & 5 \\
\hline & \multicolumn{5}{|c|}{ Antibiótico prévio } \\
\hline & Sim & Não & Sim & Não & Total \\
\hline Cultura positiva & 1 & 0 & 0 & 20 & 21 \\
\hline Cultura negativa & 12 & 8 & 1 & 20 & $\begin{array}{l}41 \\
62\end{array}$ \\
\hline
\end{tabular}


pacientes que desenvolveram úlcera corneana eram usuários de lente de contato. ${ }^{(1)}$ Este fato poderia ser justificado neste estudo em que a maioria das UCI ocorreram em pacientes idosos $(66,12 \%)$.

O uso de colírios fortificados de cefalotina e gentamicina, ou quinolona obteve $91,9 \%$ de cura nos 62 casos nesse estudo, semelhante ao encontrado no trabalho de Ly et al. $(89 \%)^{(12)}$. McLeod et al. ${ }^{(5)}$ evidenciaram que a maioria das UCI adquiridas na comunidade apresentou resposta satisfatória ao tratamento empírico de largo espectro, sugerindo que para infecções corneanas comunitárias o tratamento deve ser com o esquema clássico de associação de colírios fortificados, especialmente naqueles locais onde não é possível realizar exames laboratoriais, sugestão compartilhada por outros auto$\operatorname{res}^{(13)}$.

A introdução no mercado de colírios antibióticos não fortificados, como as quinolonas, com habilidade de chegar a uma concentração inibitória mínima para a maioria das bactérias, ter baixo custo, $\mathrm{pH}$ estável e baixo risco de contaminação trouxe comodidade e segurança para o tratamento das úlceras corneanas. Visto que os antibióticos fortificados devem ser usados simultaneamente (cefalotina $50 \mathrm{mg} / \mathrm{ml}$ e gentamicina $14 \mathrm{mg} / \mathrm{ml}$ ), causam toxicidade a superfície epitelial, têm uma vida curta e além disso requerem um farmacêutico para prepará-lo o que adiciona custo e aumenta o risco de contaminação. ${ }^{(14)}$

O relevante papel do laboratório em úlceras de córnea é bem documentado principalmente em úlceras graves, nos casos com resposta desfavorável ao tratamento clínico inicial, além de obter dados a respeito dos agentes infecciosos causadores e resistência bacteriana aos antibióticos freqüentemente utilizados.

O uso tópico de antibióticos fortificados ou quinolonas foi eficaz no tratamento das ceratites de provável etiologia infecciosa com culturas positivas e negativas. Este resultado auxilia o Oftalmologista geral, trabalhando em locais de difícil acesso ao laboratório, conseguir, possivelmente, um bom resultado no tratamento de ceratite infecciosa com a associação de antibióticos fortificados ou quinolona.

\section{Conclusão}

O uso tópico de antibióticos fortificados ou quinolona foi eficaz no tratamento das ceratites de provável etiologia infecciosa com culturas positivas e negativas.

\section{REFERÊNCIAS}

1. Alves MR, Andrade BBA. Úlcera de córnea bacteriana. Arq Bras Oftalmol. 2000;63(6):495-8.

2. Srinivasan M, Gonzales C, George C, Cevallos V, Mascarenhas $\mathrm{J}$, Asokan B, et al. Epidemiology and aetiological diagnosis of corneal ulceration in Madurai, south India. Br J Ophthalmol. 1997;81(11):965-71.

3. McDonnell PJ, Nobe J, Gauderman WJ, Lee P, Aiello A Trousdale M. Community care of corneal ulcers. Am J Ophthalmol. 1992;114(5):531-8. Comment in: Am J Ophthalmol. 1993;115(3):402-3. Am J Ophthalmol. 1992;114(5):630-2

4. Castro RS, Chinzon DV, Arieta CEL. Avaliação da terapêutica, evolução e fatores de risco para úlcera de córnea em serviço universitário. Arq Bras Oftalmol. 1992;55(1):3-6.

5. McLeod SD, Kolahdouz-Isfahani A, Rostamian K, Flowers CW, Lee PP, McDonnell PJ. The role of smears, cultures, and antibiotic sensitivity testing in the management of suspected infectious keratitis. Ophthalmology. 1996;103(1):23-8. Comment in: Ophthalmology. 1996;103(8):1165-6.

6. Paro G, Zanardo S, Chicani CF, Gomes JAP, Lima Filho AAS, Cunha MC. Correlação entre bacterioscopia e cultura nas úlceras de córnea e as implicações do uso de antibiótico prévio. Rev Bras Oftalmol. 1998;57(11):823-7.

7. Oliveira ADD, Costa IC, Sansoni A, Serapião M, Araújo MEXS Correlação clínico-laboratorial de úlceras infecciosas de córnea. Arq Bras Oftalmol. 2002;65(4):431-4.

8. Andrade AJM, Vieira LA, Höfling-Lima AL, Yu MCZ, Gompertz OF. Análise laboratorial de ceratites fungicas em Serviço Universitário. Arq Bras Oftalmol. 2000;63(1):59-63.

9. Furlanetto RL, Andreo EG, Finotti IG, Arcieri ES, Ferreira MA, Rocha FJ. Epidemiology and etiologic diagnosis of infectious keratitis in Uberlandia, Brazil. Eur J Ophthalmol. 2010;20(3):498-503

10. Rodman RC, Spisak S, Sugar A, Meyer RF, Soong HK, Musch DC. The utility of culturing corneal ulcers in a tertiary referral center versus a general ophthalmology clinic. Ophthalmology. 1997;104(11):1897-901.

11. Jeng BH, Holsclaw DS, Kumar AB, Whitcher JP, Wong IG, Margolis TP, Gritz DC. Epidemiology of corneal ulcers in northern California. Invest Ophthalmol Vis Sci. 2003;44:EAbstract 805 .

12. Ly CN, Pham JN, Badenoch PR, Bell SM, Hawkins G, Rafferty DL, McClellan KA. Bacteria commonly isolated from keratitis specimens retain antibiotic susceptibility to fluoroquinolones and gentamicin plus cephalothin. Clin Experiment Ophthalmol. 2006;34(1):44-50. Comment in: Clin Experiment Ophthalmol. 2006;34(1):3-5.

13. Pharmakakis NM, Andrikopoulos GK, Papadopoulos GE, Petropoulos IK, Kolonitsiou FI, Koliopoulos JX. Does identification of the causal organism of corneal ulcers influence the outcome? Eur J Ophthalmol. 2003;13(1):11-7.

14. Gangopadhyay N, Daniell M, Weih L, Taylor HR. Fluoroquinolone and fortified antibiotics for treating bacterial corneal ulcers. Br J Ophthalmol. 2000;84(4):378-84.

\section{Endereço para correspondência \\ Flávia Pelinsari Lana \\ Rua Doutor Diogo de Faria, $n^{\circ} 1104$ \\ Vila Clementino \\ CEP 04037-003 - São Paulo (SP), Brazil}

Tel: (11) 7660-5766 / 7021-3368

e-mail: flavia_pl@yahoo.com.br 